Original Research Paper

\title{
Solutions to Managing Drought and Reducing Demands
}

\author{
Saeid Eslamian, Saleh Tarkesh Esfahani and Kaveh Ostad-Ali-Askari \\ Department of Water Engineering, College of Agriculture, Isfahan University of Technology, Isfahan 84156-83111, Iran
}

\author{
Article history \\ Received: 19-05-2018 \\ Revised: 23-06-2018 \\ Accepted: 28-07-2020 \\ Corresponding Author: \\ Kaveh Ostad-Ali-Askari \\ Department of Water \\ Engineering, College of \\ Agriculture, Isfahan University \\ of Technology, Isfahan 84156- \\ 83111, Iran \\ Email: ostadaliaskari.k@of.iut.ac.ir \\ kaveh.oaa2000@gmail.com
}

\begin{abstract}
Conserving and saving water during droughts need a special attitude and great attention. Because according to a variety of studies conducted, nowadays our demand and need for water far exceed the amount of water resources available in different areas. As a result, in order to cope with this crisis, it is necessary to use water-recycling systems, reduce demands, employ optimal equipment for water consumption and use other methods which will be discussed in this study.
\end{abstract}

Keywords: Drought, Drought Management, Demand Reduction

\section{Introduction}

Drought is counted as one of the severe and critical climatic problems in the world. Nowadays, there is a global concern to cope with this natural disaster (Salas et al., 2005) (Fig. 3). A drought is a phenomenon that may occur at any time and in any places and in case of unpreparedness to confront it, this phenomenon can cause economic, social and environmental problems (Woods, 1989). Therefore, it is essential to reduce the damage caused by this phenomenon through the planning and implementation of crisis management. The performance of water apply limitations in a given region is very much related to the intensity of an evolving drought; thus, water management agencies such as City Water Departments often face the query of how exigent or intense a specific drought incident is (Sheffield et al., 2009). Comprehension templates of herbage population fatality during extreme weather incidents is significant to protection planners because the periodicity of such incidents is attended to enhance, creating the require to complete climatic hesitancy into management. Climate alteration is change sorts dispensations, thereby entangling protection endeavors. Protection cartographers must realize how climate drives ecological variations at spatial and time scales pertinent to man-made intention making (Lo Gullo and Salleo, 1993). Movements in drought intensity, period and alternation recommend that soil moisture droughts have become more intense, extended and periodic. Drought periodicity and intensity are forestalled to enhances across numerous continental inners, the results of these alters for dominant herbages are mostly uncertains (Gitlin et al., 2006).

Drought usually occurs with continuous periods of reduction in soil moisture and water supply, which is lower than its normal level for the environment and society (Wang et al., 2011). Nowadays, drought is examined from several perspectives that include: (1) meteorological, (2) agricultural, (3) hydrological and (4) economic perspectives.

From a meteorological perspective, a drought is a period of reduction in natural precipitation and moisture sources (Mueller et al., 2005). From an agricultural perspective, a drought is a period, during which soil moisture is insufficient for the beginning of the growing season, as well as for the tolerance and sustainability of crops. From a hydrological perspective, a drought is a period, during which the flow of streams is lower than its normal level and reserves of water reservoirs decrease and finally, the economic drought refers to its effects on human activities and consequently physical processes in the area (William et al., 1989).

\section{Materials and Methods}

\section{Drought Management Solutions}

The motivated procedure to drought management is depend on measures devised and performed before, 
during and after the drought incident, pursuant to a sketching plan rather than within a crisis framework (Moncur, 1987). The values taken before the beginning of a drought occurrence contain of longterm measures oriented to meliorate the validity of the water supply system to meet future demands under drought positions (Agthe and Billings, 2005). The prcesses taken after a drought is anticipated or begins are short-term rocesses that effort to reduce the effects of the specific drought on the base of a possiblity procedure (Benson and Clay, 1994). Drought moves can have potentially great, but many differentiated economy-wide effects, relying on the structure and resource fundings of an financials. Studies conducted have shown that water management activities dramatically affect the amount of monetary and nonmonetary losses resulting from droughts (Shih and ReVelle, 1995). Drought management solutions can be divided into three categories: (1) Measures to reduce demands, (2) Increasing the efficiency of water supply and distribution systems, (3) Water supply when necessary (Mays, 2005).

\section{Measures to Reduce Demands}

1) Measures to educate the general public in order to encourage them to volunteer to conserve and save water

2) Free distribution of water and/or installing special water conservation equipment instead of allocating water subsidies (this will lead to an increase in domestic production as well as optimal use of water).

- Low-flow shower heads

- Shower flow limiters

- Lever taps

- Pressure reducing valves

3) Restricting unnecessary consumptions

- Filling personal decorative and recreational pools

- Washing cars

- Irrigation of lawns in private yards and gardens

- Irrigation of personal playgrounds

- Washing sidewalks with water hoses

- Washing streets with water flows

- Use of ventilation and cooling systems without water circulation cycles

- Use of urban fountains on ordinary days

4) Set necessary prices during droughts (Rossi, 2000)

- Increasing all water bills based on drought costs

- Increasing all water bills based on summer consumption costs

- Increasing water bills based on costs in excess of the average consumption
5) Rationing programs

- Based on the distribution of capital, in residential areas

- Based on the number of families in residential areas

- Based on use preferences

- $\quad$ Based on reduced consumption percentages as a result of optimizing commercial and institutional costs

- $\quad$ Based on reduced consumption percentages in industrial uses

- Temporary shutdown of high-consuming industrial and commercial installations

Increasing the Efficiency of Water Supply and Distribution Systems (William et al., 1989)

1) Raw water resources

2) Water treatment installations

3) Distribution systems:

- Reducing the system pressure to the lowest level possible

- Implementing programs to find leakages and fix them

\section{Water Supply When Necessary}

1) Water transportation into areas (provinces)

- Water transportation using water tankers

- Water transportation using railway vehicles

2) Deviation from joint objectives:

- Reducing the release of reserves for hydroelectric power generation

- Reducing the release of reserves for flood control

- Diversion of water from water recreational facilities, such as artificial ponds

3) Secondary necessary resources (Mays, 2005)

- Use of water gathered into obstacles on rivers and ponds and inside mines

- Use of stagnant storage resources

- Construction of temporary pipelines in order to use remote water resources

- Reactivating abandoned wells

- Digging new wells

- Cloud seeding

- Use of refined wastewater and sewage

- Use of them in industries

- Use of them to wash streets and sidewalks

- Use of them in urban fountains 
- Use of them in resources that support firefighting systems

\section{Demand Reduction}

The increase in water prices for home uses has been the subject of a lot of research and studies. Most of these studies are inclined to analyzing the effects of urban water pricing and the way it affects water saving and conservation during droughts (Kenney et al., 2007). According to Jordan (1994), water pricing is more effective than other water conservation activities mentioned above. Because customers have limited amounts of money. For every one percent increase in the cost of access to water, some decrease in demand can usually be seen (Agthe and Billings, 2005; Moncur, 1987).

\section{Demand Models}

A demand function establishes a relation between the purchase of goods, income and other variables. The demand curve usually has a negative slope, in which a lower price corresponds to a greater demand. A general form of the variable "demand" is as follows:

$$
d=f\left(x_{1}, x_{2}, \ldots \ldots, x_{k}\right)+\in
$$

where, $f$ is a function of the variables " $x_{1}, x_{2}, \ldots \ldots, x_{k}$ " and $\epsilon$ the random error. Based on this rule, several formulas have been developed in the world. For example, in 1980, Agthe and Billings formulated the following demand function for the city of Tucson in the state of Arizona:

$$
\begin{aligned}
& \ln (d)=-7.36-0.267 \ln (P)+1.61 \ln (I) \\
& -0.123 \ln (D I F)+0.0897 \ln (W)
\end{aligned}
$$

where, $d$ is the average monthly household water consumption in $100 \mathrm{Ft}^{3}, \mathrm{P}$ the cost price of the average household consumption calculated in cents per $100 \mathrm{Ft}^{3}$, DIF the difference between the actual water consumption and sewage, I the income of each household per month and $\mathrm{W}$ the amount of evapotranspiration minus rainwater. The positive coefficient of $\mathrm{W}$ indicates that the demand logarithmically increases with $\mathrm{W}$. The above equation can be arranged as follows:

$$
d=0.00006362 P^{-0.267} I^{1.61}(D I F)^{-0.213} W^{0.0897}
$$

The price-demand fluctuation for this equation is equal to -0.267 . Therefore, changing the price when the rest of the variables are considered constant, causes a difference equal to $P_{i}^{d}$ in the average values of demand (Mays, 2005) (Fig. 1).
(A) Incremental pricing considering the consumption in excess of the consumption pattern, as well as the consumption in excess of the season consumption, (B) Incremental pricing considering the consumption in excess of the consumption pattern, (C) Uniform pricing along with service providing costs.

\section{The Compete of Drought Early Alarming and Data} Systems (Wilhite et al., 2014)

Early Warning Systems (EWS) target to decrease vulnerability and meliorate answer capacities of public at peril. Administrations retain Early warning systems to notify their nationals and themselves about imminent risks, resulting for instance, from health, geologic or climate and weather-related drivers. Seasonality already prepares intention makers with obvious symptoms of areas that are potentially at peril. Decision-making modality pertains in part on the data existent and the manner in which this data is processed by individuals, groups and systems as noted by, the timing and form of climatic data inputs (including forecasts and projections) and availability to credenced instruction and ability to explicate and performance the data and plans in decision-making processes, are as serious to individual users as betterments in prognostication expertise (Wilhite et al., 2014).

Natural catastrophes are a result of the interactions between the weather and climate extremes and the vulnerability of human and natural ecosystems to such excessives. investigation displays that the frequency and magnitude of extreme incidents is on the rise. According to, the world experienced inimitable high-impact climate excessives during the 2001-2010 decade, which was the warmest since the start of modern measurements in 1850. The decade finishing in 2010 was an unexampled era of climate excessives, as proved by heat waves in Europe and Russia, droughts in the Amazon Basin, Australia and East Africa and huge storms like Tropical Cyclone Nargis and Hurricane Katrina. Exposure and vulnerability to natural perils is enhancing as more people and physical properties are located in regions of high hazard (Wilhite et al., 2014).

\section{Describing Drought Policy}

As a beginning point in the discussion of national drought policy, it is significant to recognize the different types of drought policies that are existenting and have been used for drought management. The procedure most often followed by both expanding and expanded countries is post-impact government (or nongovernment) intermediations. A second type of drought policy procedures is the extension of preimpact government plans that are wanted to decrease vulnerability and effects. In the natural perils field, these types of plans or actions are generally referred to 
as mitigation processes. The last type of policy answer is the extension and performance of preparation programs and policies, which would include organizational frameworks and operational disciplines expanded in advance of drought and retained between drought events by government or other entities. This procedure shows an effort to engender greater institutional capacity concentrated on amended coordination and collaboration within and between levels of government and with stakeholders in the plethora of private organizations with a vested concern interest in drought management (Wilhite et al., 2014) (Fig. 2).

\section{Principal Components of a Drought Risk Decrease Policy Framework}

Drought policy elections should be prepared in each of four element regions: (1) Peril and early alarming, containing vulnerability analysis, effect evaluation and relationship; (2) reduction and provided, containing the use of beneficial and affordable execerises; (3) awareness and training, containing a well-informed public and a participatory procedure; and (4) policy governance, containing political obligation and liabilities (Wilhite et al., 2014).
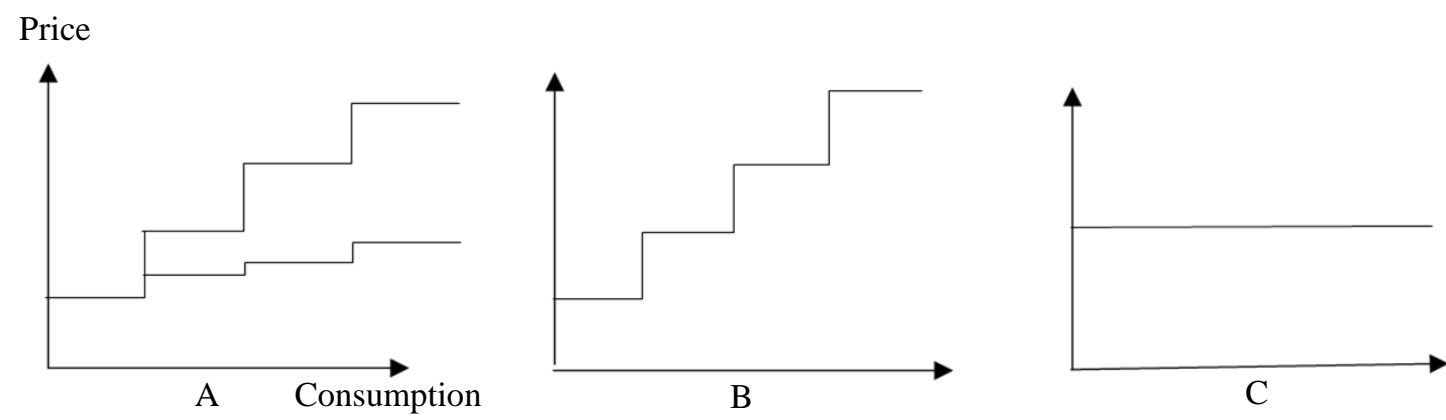

Fig. 1: Three options from among options common in urban pricing

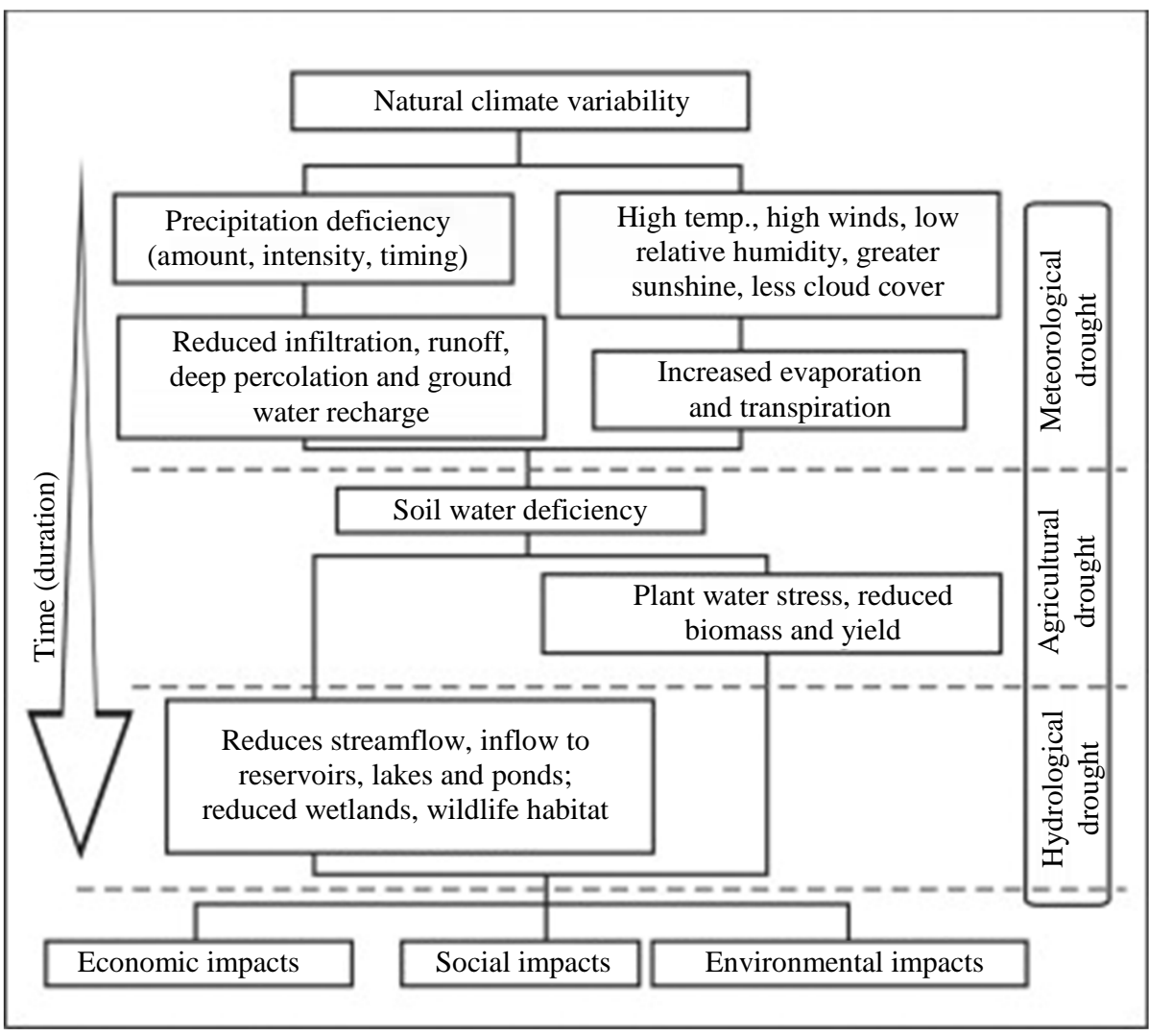

Fig. 2: Drought types, causal factors and their usual sequence of occurrence (Wilhite et al., 2014) 


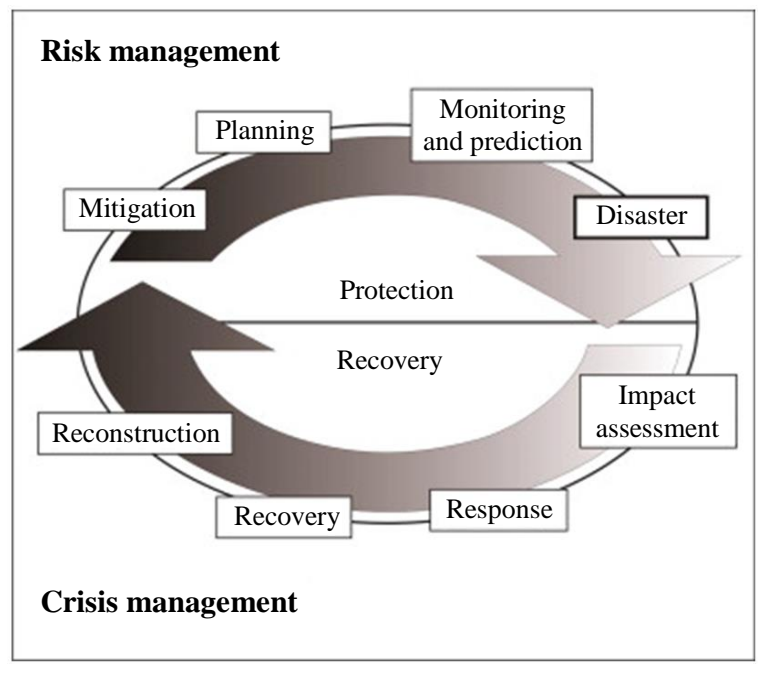

Fig. 3: Cycle of disaster management (Wilhite et al., 2014)

1. Appoint a drought task force or committee

2. State the purpose and objectives of the drought mitigation plan

3. Seek stakeholder input and resolve conflicts

4. Inventory resources and identify groups at risk

5. Prepare and write the drought mitigation plan

6. Identify research needs and fill institutional gaps

7. Integrate science and policy

8. Publicize the drought mitigation plan, build awareness and consensus

9. Develop education programs

10. Evaluate and revise drought mitigation plans

Fig. 4: 10-Step drought planning process; Source: National Drought Mitigation Center (Wilhite et al., 2014)

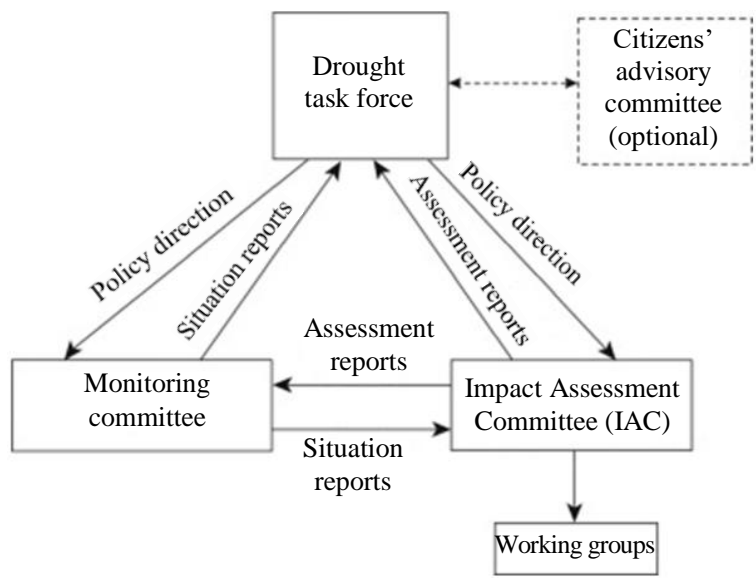

Fig. 5: Organizational structure or framework for drought preparedness plans (Wilhite et al., 2014)

\section{Drought Policy Targets}

These goals would probably (Wilhite et al., 2014):
- Eulogize defenseless economic parts and population groups to adopt self-reliant measures that advance risk management

- Advance supportable apply of the agricultural and natural resource basis

- Simplify early improvement from drought through processs consistent with national drought policy goals

- Proactive mitigation and projecting processes, hazard management, public development and resource supervision

- Greater cooperation to enhance the national/regional/global scrutiny networks and information delivery systems to amend public comprehension of and providedness for, drought

- Interpolation of general governmental and private insurance and fiscal plans into drought provided projects

- Diagnosis of a security net of emergency alleviation depended on sound superintendency of natural resources and self-help at various levels

- Accord of drought schedules and answer endeavours in an beneficial, impressive and customer-oriented treatment

State officials should inspect many inquiries as they describe the goal of the project, such as the following (Wilhite et al., 2014):

- Aim and role of government in drought reduction and answer endeavours

- Area of the project

- Most drought-prone regions of the country/territory

- Historical effects of drought

- Historical answer to drought

- Most weak economic, social and environmental parts

- Role of the program in resolving velitation between water gainers and other vulnerable groups during periods of shortage

- Current trends (e.g., land and water apply, population growth) that may increase/vulnerability and tensions in the future

- Resources (human and economic) that the government is inclined to perform to the planning process (Fig. 4 and 5)

- Legal and social concepts of the project

- Principal environmental anxieties caused by drought

\section{Result and Discussion}

Drought mitigation actions contain a large number of moves, which can be grouped into three wide classes: Supply-enhancement, demand diminution and drought effect reduction (Rossi et al., 2005). Each classes relics the physical, economic and societal effects of drought in 
various procedures. It is essential of moving from a reflexive procedure to a proactive procedure is considered. The second procedures needs progress preparation of both long-term moves oriented to decrease vulnerability of water store systems and short-term actions to be taken during the drought cycle. The impress of a drought monitoring method and an suitable institutional substructure for impressive drought management is also attentioned. The apply of multicriteria procedures to contrast various drought diminution processes and pick up the suitable compound of moves is advocated. The science of the action of a water supply system during hydrological drought incidents is beneficial to recognize the risk of deficiencies and to undertake the essential processes to decrease drought effects.

With the universal warming, frequencies of drought are rising in the humid zone. The relics of meteorological drought on the agricultural water resource depend on the agricultural water resource carrying capacity is essential. Our discoverys highlight the significance of modifying the relations of crop planting to modify the utilization efficiency of agricultural water resources and reduce drought hazards in some humid regions. Droughts are many extensive natural catastrophes, which cause the most intense fatality among natural catastrophes. Societies in zones with seasonal rainfall countenance annual dry seasons, during which water deficiencies and contradictions between various water apply sectors may erupt. The index can help water directors to plan ahead and negotiate the require for water protection (demand management) and attention of other water sources such as rain and surface water (supply management). Data used from drought analysis can serve as the base for water resources projecting and management under the conquering climate change situation mostly at the basin scale. But, given the planned global warming situations, a return of the present normal situation might be observed in the nearest future, therefore, the consequences of this reading can serve as a base for beneficial water resources projecting and management in the basin. Most citified coastal town absence freshwater resources and depend on water supply from next inshore watersheds. It is essestial to perform the important management procedures with the diminution in precipitation and water resources in the area. Multiple menances, containing universal climate alteration and different human activities, relic both the quantity and quality of fresh water existent. Lack of the management causes many problems which one of them is very vital can be pointed to enhanced water expenses.

\section{Conclusion}

Given the reduction in precipitation and water resources in the province and prediction of drought, it is necessary to implement the aforementioned management methods and to increase water costs in the coming years. Distribution of optimal fittings and valves is an appropriate solution among the aforesaid solutions. In addition, considering the way water is used by consumers, it is essential to provide educational programs to enhance the culture of water consumption simultaneously with the implementation of the said methods.

\section{Acknowledgment}

This work reported in this study is a part of a project on improving water resource management funded by Isfahan University of Technology, Isfahan, Iran.

\section{Author's Contributions}

All authors equally contributed in this work.

\section{Ethics}

In addition, this study was conducted in accordance with the Declaration of Natural Resource Governance Institutein Iran (Isfahan University of Technology) and the protocol was approved by the Ethics Committee.

\section{References}

Agthe, D. E., \& Billings, R. B. (2005). Dynamic models for residential water demand. Water Resource, 16, 470-489.

Benson, C., \& Clay, E. (1994). The Impact of Drought on Sub-Saharan African Economies. ids bulletin, 25(4), 24-32.

Gitlin, A. R., Sthultz, C. M., Bowker, M. A., Stumpf, S., Paxton, K. L., Kennedy, K., ... \& Whitham, T. G. (2006). Mortality gradients within and among dominant plant populations as barometers of ecosystem change during extreme drought. Conservation Biology, 20(5), 1477-1486.

Kenney, D. S., Klein, R. A., \& Clark, M. P. (2007). Use and effectiveness of municipal water restrictions during drought in Colorado. JAWRA, 40, 77-87.

Lo Gullo, M. A., \& Salleo, S. (1993). Different vulnerabilities of Quercus ilex L. to freeze-and summer drought-induced xylem embolism: an ecological interpretation. Plant, Cell \& Environment, 16(5), 511-519.

Mays, L. W. (2005). Water resources engineering. John Wiley and Sons.

Moncur, J. E. (1987). Urban water pricing and drought management. Water Resources Research, 23(3), 393-398. 
Mueller, R. C., Scudder, C. M., Porter, M. E., Talbot Trotter III, R., Gehring, C. A., \& Whitham, T. G. (2005). Differential tree mortality in response to severe drought: evidence for long-term vegetation shifts. Journal of Ecology, 93(6), 1085-1093.

Rossi, G. (2000). Drought mitigation measures: a comprehensive framework. In Drought and drought mitigation in Europe (pp. 233-246). Springer, Dordrecht.

Rossi, G., Cancelliere, A., \& Giuliano, G. (2005). Case study: multicriteria assessment of drought mitigation measures. Journal of Water Resources Planning and Management, 131(6), 449-457.

Salas, J. D., Fu, C., Cancelliere, A., Dustin, D., Bode, D., Pineda, A., \& Vincent, E. (2005). Characterizing the severity and risk of drought in the Poudre River, Colorado. Journal of Water Resources Planning and Management, 131(5), 383-393.

Sheffield, J., Andreadis, K. M., Wood, E. F., \& Lettenmaier, D. P. (2009). Global and continental drought in the second half of the twentieth century: severity-area-duration analysis and temporal variability of large-scale events. Journal of Climate, 22(8), 1962-1981.
Shih, J. S., \& ReVelle, C. (1995). Water supply operations during drought: A discrete hedging rule. European journal of operational research, 82(1), 163-175.

Wang, A., Lettenmaier, D. P., \& Sheffield, J. (2011). Soil moisture drought in China, 1950-2006. Journal of Climate, 24(13), 3257-3271.

Wilhite, D. A., Sivakumar, M. V., \& Pulwarty, R. (2014). Managing drought risk in a changing climate: The role of national drought policy. Weather and Climate Extremes, 3, 4-13.

William, R. W., Margaret, S. H., \& Carol, J. H. (1989). Management of water resources for drought conditions; institutional and management aspects. National Water Summary, Hydrologic Events and Floods and Droughts.

Woods, P. (1989). Effects of logging, drought and fire on structure and composition of tropical forests in Sabah, Malaysia. Biotropica, 290-298. 